Historia y comunicación social

ISSN: 1137-0734

http://dx.doi.org/10.5209/hics.75704

\title{
¿Espejos o espejismos? Los cambios del septenio 1976-1982 en España y Polonia reflejados en los respectivos semanarios políticos
}

\author{
Anna Katarzyna Dulska
}

Recibido el: 30 de agosto de 2019 / Aceptado: 28 de mayo de 2020

Resumen. En el presente artículo se analizan las narrativas sobre España y su proyecto reformista contenidas en el influyente semanario polaco "Polityka" por un lado, y sobre Polonia y sus dinámicas sociales en el semanario reformista español, "Cambio 16", por el otro, generadas entre los años 1976-1982, un periodo crucial tanto para las trayectorias domésticas, como para las relaciones bilaterales entre ambos países. El estudio indaga si lo que dichos medios buscaban fue un espejo de la realidad que facilitaría un entendimiento recíproco o más bien un espejismo para apologizar la situación doméstica. Se concluye que, en efecto, los encuadres interpretativos de los contenidos informativos sobre el otro país fueron a menudo utilizados para estructurar las percepciones sociales de asuntos propios. Palabras clave: Transición política en España; historia reciente Polonia; prensa política; agenda-setting, framing.

[en] Mirrors or Mirages? Changes occurred in Spain and Poland between 1976 and 1982 as reflected in respective political weekly newspapers

\begin{abstract}
The present paper analyses narratives about Spain and Spanish transformation published by an influent Polish weekly newspaper "Polityka" on one hand, and about Poland and its social dynamics in a reformist Spanish weekly newspaper "Cambio 16", on the other. The time framework is a period from 1976 to 1982, crucial for both internal affairs, as well as for bilateral relations between the two states. The research attempts to answer the question whether these newspapers searched for a mirror that would help in mutual understanding or rather for a mirage to defend domestic situation and concludes that, indeed, interpretative framing of informative contents on the other country were frequently used to structure social perceptions of own affairs.

Keywords: Political transformation in Spain; recent history of Poland; political press; agenda-setting; framing.
\end{abstract}

Sumario: Introducción y el estado de la cuestión. Fuentes y metodología. Miradas cruzadas: análisis de los resultados. La Transición española en "Polityka". La «primavera» polaca en "Cambio 16". Conclusiones. Referencias bibliográficas.

Cómo citar: Dulska, A. K. (2021) ¿Espejos o espejismos? Los cambios del septenio 1976-1982 en España y Polonia reflejados en los respectivos semanarios políticos, Historia y comunicación social 26(1), 107-120.

\section{Introducción y el estado de la cuestión}

La comparativa entre contenidos internacionales en los medios de comunicación de diferentes países resulta de sumo interés para los historiadores, pues permite captar una realidad invisible para otros tipos de fuentes históricas: los imaginarios y las percepciones mutuas. Tal es el caso de las relaciones entre España y Polonia en el siglo XX. Los estudios sobre ellas como también sobre los paralelismos históricos son abundantes, pero se centran sobre todo en la Guerra Civil Española o en la comparativa de los procesos de la transición de ambos estados (Barabasz, 2016; Bednarczuk, 2008; Białokur, 2012; Czajka, 1980; Dobek-Ostrowska, 1996; Faraldo, 2016; González Martínez \& Nalewajko, 2005; Kieniewicz, 2004; Kudełko \& Taracha, 2012; Marina, 2008; Mizerska-Wrotkowska \& Orella Martínez, 2014; Mleczak, 2013; Opioła, 2016; Różycki, 2015; Wojna, 2004). El presente artículo, en cambio, tiene por objetivo indagar los imaginarios y percepciones sincrónicos que ambos países tenían de si en los neurálgicos tiempos del septenio 198-1976, cuando España pasaba por el periodo reformista de la Transición de la dictadura franquista a la democracia (1976-1982), mientras que Polonia parecía vivir un efervescente despertar de la oposición contra el régimen comunista que surgió a raíz 
de los acontecimientos de junio de 1976, condujo a la creación de la "Solidaridad" en 1980 y el posterior «carnaval de la democracia» y fue fulminado por la introducción de la ley marcial en diciembre de 1981; máxime que en 1977, tras casi tres décadas de una ignorancia formal suavizada por una serie de acuerdos de índole económica (Bernatowicz-Bierut, 1978: 309-315; Różycki, 2015: 361-362; 367-371), fueron reanudadas las relaciones diplomáticas bilaterales.

Ante las dificultades en reconstruir de forma sistemática la opinión pública de aquel periodo y valiéndose del marco teórico proveniente de las ciencias de comunicación, concretamente la teoría del agenda-setting en el presente estudio se propone estudiar la proyección mediática de ambos países y el trasfondo político de los comunicados periodísticos relevantes. Según la teoría del agenda-setting los medios de comunicación, siendo la principal fuente de la información sobre el mundo, reflejan una específica visión de la realidad, filtrando los contenidos, destacando unos y omitiendo otros, y establecen así la agenda que prioriza en qué ha de pensar la sociedad. Además, proveyendo el público con unos marcos cognitivos, estructuradores e interpretativos concretos (framing) encauzan a su manera el có mo ha de pensar (Cohen, 1963: 13; McCombs, 1996 \& 2004; Reese, Gandy, Jr. \& Grant, 2001; Rubio Fuentes, 2009; Sádaba Garraza, 2008; Scheufele, 2000; Iyengar, 1991). Parafraseando un dicho polaco según el cual "tal como te ven, así te escriben", se puede decir que tal como te describe la prensa, así te ve la sociedad.

En su libro España en el espejo polaco (2001: 15) Jan Kieniewicz, historiador y embajador de Polonia en Madrid en los primeros años de la transición polaca a la democracia (1990-1994) insistió en que los polacos deberían no solo conocer España, sino que también entenderla, pues los problemas con los que ambos países tuvieron que enfrentarse en sus historias recientes tuvieron un denominador común: la libertad. Por su parte, comentando un relato de viaje de una escritora española a Polonia del año 1967, otro diplomático, Javier Rupérez, en cuyo cursus honorum destaca para el tema aquí tratado el cargo del primer secretario de la Representación Consular y Comercial en Varsovia (1969-1972), afirmó que las experiencias polacas son muy distantes al mismo tiempo que gemelamente parecidas a las españolas (Rupérez, 2012: 150). Arroja también cierta luz sobre qué pensaban los unos sobre los otros (2012: 146-147, trad. aut.):

Polonia era un espejo en el cual podía observar un reflejo de mis experiencias españolas. La Polonia socialista nos adelantaba, por supuesto, en cuanto a la presencia y prestigio en el tablero internacional, pero las condiciones de vida del país se presentaban con una gran desventaja frente a las nuestras. (...) me tomaban con reserva tanto mis amigos polacos, convencidos que España estaba envuelta en una oscura mortaja de la dictadura, como mis amigos progresistas en España, poco dispuestos a creer que en un país socialista pudiera haber menos pan y libertad que en la España franquista.

Resulta llamativo que tanto Kieniewicz, como Rupérez utilizaran la metáfora del espejo. En efecto, una de las funciones del relato mediático es reflejar e interpretar la realidad. Sin embargo, lo que a veces se busca es espejar no tanto la realidad que se describe- en este caso de un país lejano-, sino aquella dentro de la cual el relato se produce, como si de un espejismo se tratara. Así, en búsqueda de los espejos y/o tal vez espejismos polaco-españoles, se analizará la narrativa sobre Polonia y las dinámicas sociales reformistas polacas en el semanario reformista español "Cambio 16" (en adelante "C16") por un lado, y sobre España y el proyecto reformista español en uno de los más influyentes semanarios polacos, "Polityka" (en adelante "P"), por el otro. Analizando la agenda que establecían y cómo la encuadraban, se tratará se responder a la pregunta de si buscaban un espejo que facilitaría un entendimiento mutuo entre ambas sociedades o más bien un espejismo para apologizar la situación doméstica.

\section{Fuentes y metodología}

La selección del tejido del estudio, de los dos semanarios políticos (consultados en original en hemerotecas), fue motivada principalmente por dos razones. En primer lugar, ambos semanarios mantuvieron su continuidad en todo el periodo aquí tratado sin alterar su periodicidad ni formato (como fue por ejemplo el caso de "Triunfo" o "Cuadernos para el diálogo"). En segundo lugar, por su orientación política. "C16", de corte centro-progresista, fue fundado en 1971 como revista socio-económica, pero tres años después se orientó hacia la política y daba cobertura a la actualidad española e internacional, preocupándose especialmente por "los vientos de cambio" que soplaban desde diferentes direcciones (Díaz Dorronsoro, 2010; 2012). Siendo el «estandarte de los cambios democráticos» (Pérez López, 1997: 101), no sería descabellado considerarlo como la revista «oficial» de la Transición. Por su parte, "P" fue creada en 1957 como semanario oficial del Partido Obrero Unificado Polaco (POUP) con la intención de que fuera el pregonero socio-político de los cambios promovidos por el mismo. Su perfil político fue, naturalmente, de izquierdas (hasta 1990 el lema de la portada era “¡Proletarios de todos los países, uníos!”), pero poseía cierta tonalidad liberal, dentro de los límites establecidos por la censura (Władyka, 2007; sobre la situación general de los medios de comunicación en la República Popular de Polonia [Polska Rzeczpospolita Ludowa-PRL] véase entre otros: Wolsza \& Ligarski, 
2010; Malinowski, Niwiński \& Dmochowski, 2003). Al igual que en el caso de "C16", una parte significativa de "P" estaba dedicada a la sección internacional. Así, ambos semanarios eran reflejos de sus tiempos en los respectivos países y manteniendo la línea por ellos marcada, su misión consistía en interpretar los acontecimientos domésticos y del extranjero para sus lectores, convirtiéndose asimismo en unos agendasetters por excelencia. Además, en el contexto del imaginario hispano-polaco, cabe añadir que ambas revistas a menudo se citaban mutuamente como fuentes de referencia. Véase por ejemplo Skulska (29-05-1976) quien considera a "C16" como un semanario excelente, o Kelepikis (6-11-1977a) quien califica a "P" como liberal.

Ahora bien, ambos semanarios ¿consideraban relevante este imaginario? Considerando como el criterio de elección de textos su dedicación parcial o completa a Polonia y España respectivamente, sean de índole política, económica, social o cultural o mixta, en total fueron publicadas 197 piezas, 132 en "C16" y 65 en "P". El siguiente gráfico ilustra la frecuencia con la que ambos semanarios publicaban contenidos relevantes, como también su tipología. Dada su importancia para el periodo aquí tratado, se incluye también los datos relativos al año 1975.

Figura 1. Distribución temporal y tipología de los contenidos sobre Polonia en "C16" y sobre España en "P" entre 1975-1982

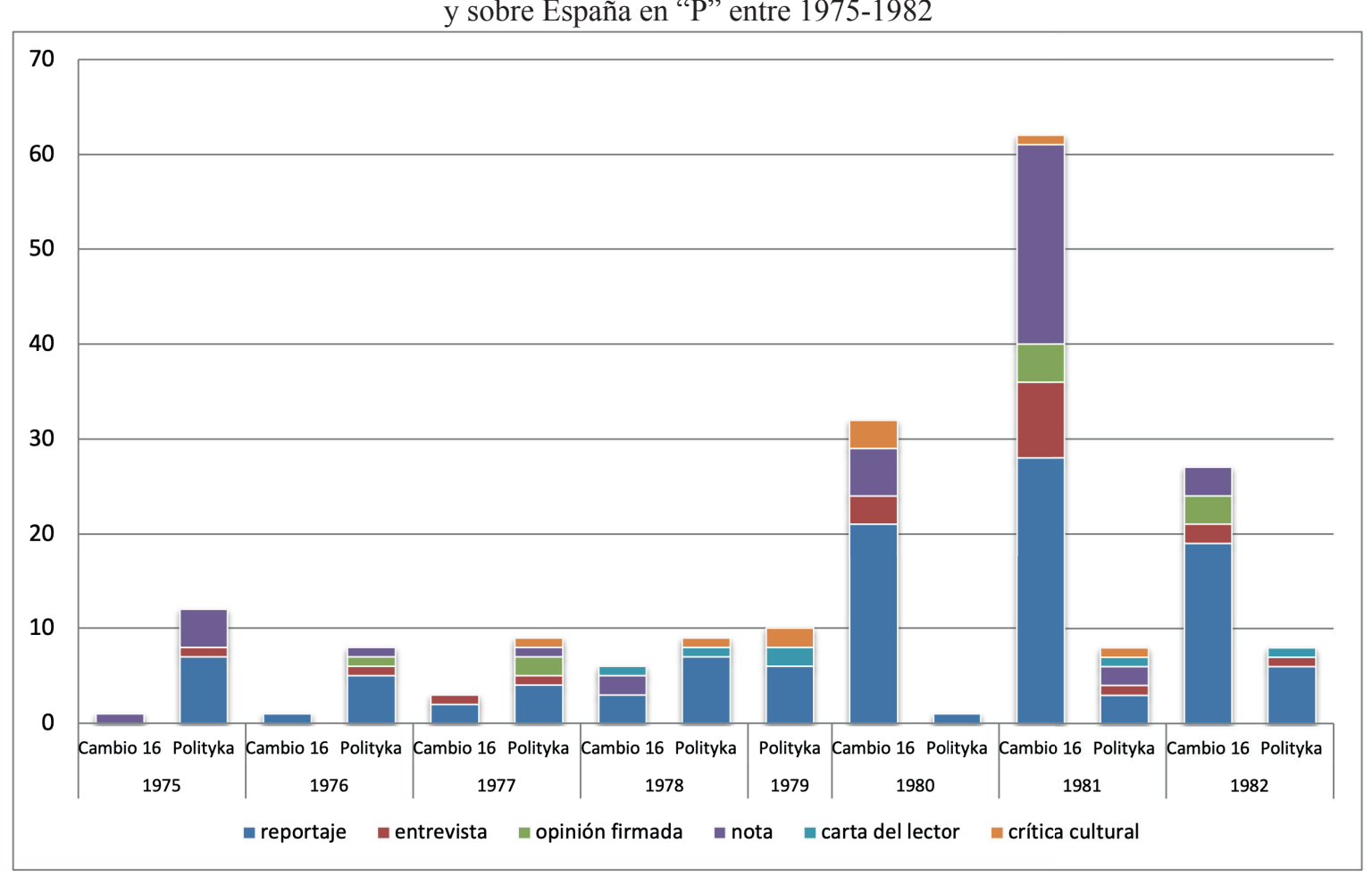

Fuente: elaboración propia

Como se puede observar, la distribución temporal del "interés" mutuo es muy desigual. En el caso de "P" el interés por España fue más o menos constante. Menos en el año 1980, cuando apareció solamente un artículo, salía aproximadamente una decena de textos al año. El 80\% eran textos largos de diferentes tipos: reportajes, entrevistas, artículos de opinión o críticas culturales, siendo el resto unas notas breves sobre la actualidad más reciente, cartas de los lectores o respuestas a éstas.

Por su parte, en el caso de "C16", salvo una nota de junio de 1975 sobre la visita de Giscard d'Estaing y apertura de una nueva línea de crédito a cambio de carbón (S/N, 30.06.1975), en 1975 y 1976 Polonia fue solamente mencionada en artículos que abarcaban temas más amplios. Es desde 1977 (3) cuando se le dedican un espacio propio. El interés aumenta claramente en 1978 (6), concretamente en otoño, tras la elección pontificia de Karol Wojtyła, "un Papa eslavo, impactado por una experiencia política, económica y social sui generis, difícil de comprender por nosotros" (Miret Magdalena, junio 1979: 14). Tras un silencio en 1979, en 1980, a causa de las dinámicas polacas el interés se desploma (32), llegando al máximo en 1981 (62), para disminuir paulatinamente al año siguiente (27).

El estudio se ha centrado en el análisis crítico de contenido de dichas publicaciones con el fin de identificar rasgos que definían los imaginarios mutuos entre ambos países y discernir sus contenidos informativos sobre el país-objeto (espejo) de aquellos de carácter interpretativo que mediante su encuadre hacán una referencia tácita a la actualidad del país-sujeto (espejismo). 


\section{Miradas cruzadas: análisis de los resultados. La Transición española en "Polityka"}

\section{Año 1976}

El advenimiento de la nueva época en España se anunciaba en "P" desde mediados del 1975 con un artículo reimpreso de Frankfurter Allgemeine sobre la discusión en torno a las responsabilidades por el fusilamiento de Federico García Lorca (Haubrich, 27-09-1975). Hasta el fin de año fueron publicados varios análisis de diferentes aspectos de la actualidad española: la actividad de ETA y la situación en el País Vasco (Jaranowski, 4-10-1975), la situación social y de los medios de comunicación (Passent, 4-10-1975), una entrevista con Enrique Tierno Galván, fundador del Partido Socialista Popular (PSP) sobre la formación de la oposición social y política al régimen y la relación entre PSP y el Partido Comunista de España (PCE) (Iwiński, 8-111975), un panorama de la situación general esbozado a base de los relatos e informes de los medios de comunicación occidentales y los corresponsales polacos en Madrid y Bruselas (Zdanowski, 15-11-1975), el entierro de Franco en el Valle de los Caídos y las perspectivas del desarrollo de la situación tras su muerte (Górnicki, 29-11-1975), con un interés especial por la situación de la clase obrera (Ikonowicz, 6-12-1975) y la economía (Hübner, 13-12-1975). Las cuestiones más resaltadas eran las perspectivas del acercamiento de España a Europa, promovido por Opus Dei, la crítica situación económica del país, la diversificación política y, sobre todo, el fracaso de la extrema derecha y esperanzas para la izquierda. No faltaron también divagaciones sobre paralelismos entre España y Portugal.

Comenzado el año 1976, además de las notas sobre la convocatoria de las elecciones municipales donde los partidos debían adquirir experiencia política y las continuas huelgas, fue analizada la situación de uno de los pilares de la dictadura, las fuerzas armadas, y la iniciativa de la Unión Democrática Militar, su programa y el posible juicio de sus miembros por "conspiración" (Ikonowicz, 24-01-1976). Según el periódico, el juicio sería una manifestación de las intenciones democráticas del gobierno. Se intentó explicar, con claridad, la complejidad de la «primavera española», presentando «quién es quién» y cuáles eran los postulados de los diferentes grupos políticos (Skulska, 29-05-1976). Lo que más llamó la atención fue, sin embargo, el altísimo precio de gasolina $(0,5 \$ / 1$ itro), el afán de los españoles por los espectáculos (hablando de la salida de Carmen Polo del palacio de El Pardo) y la preocupación de la sociedad por su propia existencia (la inflación, el nivel de vida, el paro y las huelgas), más que la actual y futura situación política. Tras la caída de Carlos Arias Navarro y el nombramiento de Adolfo Suárez fueron esbozadas sus perspectivas, insistiendo en la difícil situación económica y social, como también en la tensión entre el búnker franquista y los reformistas (Ikonowicz, 10-07-1976). Para referirse a Suárez, hacia quien tanto la extrema derecha como la oposición se mostraron escépticas, fue citado un miembro de la Coordinación Democrática quien consideraba a Suárez "el caballo de Troya de Opus Dei". Otra cuestión de relevancia era la situación de la izquierda española. Fue relatado el pleno del Comité Central del PCE celebrado en Roma en julio donde sus líderes, entre ellos Santiago Carrillo, Dolores Ibárruri y Marcelino Camacho, jefe de las Comisiones Obreras (CCOO), anunciaron "la salida a la luz del día" y manifestaron sus demandas al gobierno de Suárez (Kedaj, 7-08-1976). Un lugar considerable de aquel artículo fue dedicado a la presencia de los cristianos en el partido, incluidos los sacerdotes. En una entrevista, Camacho expuso su visión de la transición (Ikonowicz, 6-11-1976). Calificó el gabinete de Suárez de neofranquista, apuntó al fracaso del capitalismo como causa de la crisis económica y laboral y demandó las libertades sindicales y los derechos a las manifestaciones. Finalmente, ante los cambios, se volvió a hablar sobre la Guerra Civil, presentándola no solo como un conflicto de clases de cuyo fin decidió la debilidad interna de la República, sino también como una guerra nacional-revolucionaria, con gran papel de la "hipócrita y suicida" política de los países occidentales que, bloqueando a la República mediante la no-intervención, abrieron camino al fascismo (Ryszka, 10-07-1976).

\section{Año 1977}

La transición española aceleraba. El atentado contra los letrados que defendían a los miembros de las CCOO en su despacho de Atocha en enero le sirvió a "P" de pretexto para presentar la violencia política en España (Ikonowicz, 26-02-1977).

Sin embargo, como era de esperar, la gran noticia fue la legalización del PCE (Ikonowicz, 23-04-1977). Según fueron informados los lectores, esta difícil decisión de Suárez, quien corría el riesgo de la reacción de las fuerzas armadas, fue motivada por la solidaridad de todos los demás partidos, desde los socialistas hasta los liberales (sic!), que amenazaron con no participar en las elecciones generales sin el PCE, lo cual les restaría su "credibilidad democrática". El autor advirtió que no se trataba por supuesto de un altruismo político, sino de un cálculo según el cual la ausencia del PCE podría aumentar el peso de la neofranquista Alianza Popular. Concluyó que la objeción del ejército a la legalización del PCE creó un preocupante precedente que las fuerzas armadas ganaron la prerrogativa de cuestionar las importantes decisiones políticas, debilitando asimismo a Suárez. En cuanto a las elecciones, la constatación no podría ser otra que vencedores hubo dos: UCD y PSOE, con una diferencia de "tan solo" 700 mil votos (Ikonowicz, 25-06-1977). El éxito de Suárez fue atribuido a su 
pragmatismo, realismo, flexibilidad, capital político acumulado durante los años anteriores y... a los carteles electorales donde salía "atractivo con rostro lleno de energía". El autor anotó también que la campaña "al estilo de Jimmy Carter" de Felipe González fue financiada en gran parte por el Partido Socialdemócrata Alemán (SPD). Por su parte, el bajo resultado del PCE (20 escaños) fue atribuido a que su legalización tuvo lugar solamente 40 días antes de los comicios. Terminó diciendo que las elecciones era una cosa y la vida otra y para combatir el paro, la inflación y la deuda exterior la colaboración de la izquierda sería imprescindible.

\section{Año 1978}

La redacción de "P" afirmó que "seguía con gran interés los cambios que se producían en España" (Ikonowicz, 25-02-1978). Su corresponsal empezó el año explicando los Pactos de Moncloa y destacando el carácter pacífico del desmantelamiento de franquismo (Ikonowicz, 7-01-1978), reiterando su aprecio por la sensatez política y flexibilidad de Suárez. La principal conclusión que sacó del compromiso era que abría una perspectiva real de que algún día podrían llegar al poder -cosa hasta entonces impensable-los socialistas o que un comunista podría ser ministro. Llamó su atención que conforme se reforzaba la democracia en España -hay que tener presente que la PRL se consideraba a sí misma un país democrático- menos huelgas atormentaban sus calles, a pesar de la crisis económica que afectaba gravemente al proletariado: "menos trabajo, menos pan, menos gasolina y menos huelgas". Al mismo tiempo comentó la actitud de la burguesía capitalista que se veía amenazada por las reformas fiscales de Suárez y le acusaba de "izquierdismo", pero no entendía que esto la protegía de "problemas mucho más gordos". Señaló también las crecientes demandas autonómicas en muchas regiones como oposición a 40 años del corrupto paternalismo de las autoridades centrales. Al problema del paro como medida contra la inflación, importada de Alemania Occidental, pero en España socialmente peligrosa, fue dedicado un reportaje sobre dos colectivos más interesantes para la opinión pública polaca: los obreros de grandes fábricas y el campesinado andaluz (Ikonowicz, 11-03-1978). Un lugar separado fue dedicado al independentismo canario y los vínculos del archipiélago con África (Pasierbiński, 18-03-1978), a lo cual respondió en una carta al director el primer secretario de la embajada española de Varsovia, criticando la noticia como una «intencionada manipulación» (Pons, 27-05-1978). Según el diplomático, muchos polacos viajaban a Canarias por vacaciones y podían hacerse su propia idea de la realidad canaria. Además de temas políticos, fueron tratados -todos en tono positivo- los cambios socio-culturales, tales como las nuevas tendencias en la cultura de élites y popular y el fin de la censura (Marrodan \& Schmidt, 18-02-1978), la situación de la Iglesia católica y su "divorcio" del Estado (Ikonowicz, 10-06-1978), la secularización de la sociedad y la nueva moralidad (situación de la mujer, sexualidad, contracepción, abortos etc.) (Romanowicz, 15-06-1978). Curiosamente, al gran logro del año, la Constitución, no se le dedicó un artículo separado, sino que unos días antes del referéndum se habló de ella a propósito de intento de un golpe de estado (conocido como Operación Galaxia) de los oficiales ultraderechistas en un intento de oponerse a la nueva ley fundamental que archivaría definitivamente la legislación franquista (Ikonowicz, 2-12-1978).

\section{Año 1979}

El panorama político fue analizado por "P" en un reportaje postelectoral (Ikonowicz, 17-03-1979). Según el autor, el electorado, apático, que no aprendía a pensar durante 40 años y tras la euforia de las primeras elecciones perdió de nuevo interés por la política. La UCD tomó rumbo más hacia la derecha, ganándose votos de los ultras del antiguo búnker en el cual quedó solamente lo que denominó «folklore político». Como puntos fuertes de Suárez señaló a la Constitución que acercó a España a las democracias occidentales, la reducción de la inflación, sus relaciones públicas, sobre todo la campaña televisiva y los sondeos. El resultado de PCE fue evaluado como satisfactorio, dados los escasos medios de los que disponía, mientras que el PSOE, por el contrario, fue criticado por su tibieza. Sobre la economía fue publicado un artículo que trató de explicar las razones de las dificultades que afrontaba España: el afán por la rutina, burocracia, pero a la vez improvisación, la ineficiencia laboral y productiva y complejos (Łuszczkiewicz, 24-03-1979). Los cambios de la Transición fueron atribuidos al capital extranjero, paulatinos cambios de la mentalidad (la transformación del caballero quijotesco en un ejecutivo) y a los tecnócratas de Opus Dei que tradujeron las ideas de la ética protestante de trabajo al catolicismo. Aparte, fueron tratadas las luces y sombras de la cooperación entre Polonia y España: las fructíferas sociedades comerciales conjuntas (Rumińska, 1905-1979) y también un caso de pleito entre tres fabricantes españoles de bolsos y su importador polaco, pues casi todo un lote de 11 mil unidades resultó defectuoso (Lach, 14-04-1979). Entre los productos españoles demandados en Polonia estaba el vino, anchoas, cítricos, cosméticos, cinturones de piel, ropa y... calzoncillos. En relación a la sociedad, fue citada una encuesta del "C16" que plasmaba las principales preocupaciones de los españoles: el paro (agravado por las huelgas y legislación laboral que espantaba a los inversores) y el terrorismo (Skulska, 10-02-1979). No faltaron relatos dedicados a la cultura: sobre la publicación de los diarios del secretario personal de Franco (Ikonowicz, 22-29-12-1979) y cine (Kałużyński, 7-04-1979), incluido el festival de San Sebastián (Urban, 29-09-1979). 


\title{
Año 1980
}

A lo largo de todo el año "P" publicó solamente un reportaje sobre España, del cual merecen ser destacadas dos cosas (Ikonowicz, 14-06-1980). Por un lado, de nuevo el papel de los medios de comunicación masivos, sobre todo la televisión, en la vida política del país. Por otro, el autor habló de la moción de censura que casi apartó a Suárez del poder como de una trampa autoimpuesta: habiendo realizado una transición pacífica de la dictadura a la monarquía parlamentaria, tuvo que afrontar los mecanismos constitucionales que en gran medida él mismo creó.

\section{Año 1981}

Tras la dimisión de Suárez y proclamación de Leopoldo Calvo Sotelo como nuevo presidente de Gobierno, España vivió en febrero momentos de gran tensión a causa del fallido intento de golpe de estado por las fuerzas armadas. Los publicistas de "P" vieron el 23-F como un examen para la democracia y la monarquía española (Ikonowicz, 7-03-1981). Ambas lo aprobaron y la postura del rey Juan Carlos recibió una crítica muy positiva. Interés suscitó también la cada vez más fuerte izquierda, aunque se observó que las divisiones internas dentro del PCE lo debilitaban demasiado (Kik, 13-06-1981). Por su parte, en el contexto del despertar del sindicalismo independiente en Polonia, tuvo que resultar muy sugerente para los lectores polacos la entrevista a Camacho, quien se mostró bien orientado en la actividad de "Solidaridad" y dijo que habían invitado a venir a España a Wałęsa (Skulska, 8-08-1981). Preguntado por su opinión sobre la sindicalización del campesinado contestó prudentemente que en las Comisiones no tienen razón de ser en el campo pues su destinatario eran las multinacionales y no la burocracia, como en el caso polaco. No obstante, ambos interlocutores estuvieron de acuerdo que no es justificado establecer paralelismos entre las CCOO y "Solidaridad".

\begin{abstract}
Año 1982
El año 1982 fue el epilogo de la Transición sin ruptura llevada a cabo por la UCD. En las elecciones generales celebradas en otoño el testigo del gobierno pasó al PSOE, comenzando así un capítulo nuevo en la historia reciente de España.

Sin embargo, estando Polonia en pleno estado de ley marcial, el tema "español" más ampliamente tratado en "P" fue la situación de la izquierda: dos análisis de la crisis interna del PCE (antes y después de las elecciones generales) (Kik, 20-11-1982), entre cuyas causas fue identificada la falta de consenso ante la crisis polaca y el intento de utilizarla para cuestionar el sistema soviético; y otros dos del PSOE (Kik, 12-06-1982 \& 11-121982), que a pesar de divisiones internas consolidaba efectivamente su posición, hasta obtener mayoría absoluta en las Cortes gracias a la creación de un "amplio bloque de clases". En cuanto al proyecto de la adhesión a la OTAN, orientado a afianzar las relaciones con el Occidente y asegurar la posición de la UCD, que bajo Leopoldo Calvo Sotelo giró más a la derecha, las conclusiones fueron muy pesimistas. La entrada de España a la Alianza provocaría polarización del tablero político doméstico, sobre todo ante la inminente llegada al poder de los socialistas, agravaría los conflictos dentro del ejército y en la sociedad, empeoraría la crisis económica, debilitaría la posición diplomática de España y hasta podría retar la seguridad europea (Bernatowicz-Bierut, 22-05-1982). A largo plazo podría incluso amenazar a la joven democracia. La victoria del PSOE, por su parte, fue interpretada dialécticamente como resultado de una dinámica natural de la Transición, la maduración de la democracia española y muestra de la radicalización política del sur de Europa (Bernatowicz-Bierut, 6-111982). Aludiendo la situación en la que se encontraba Polonia resulta llamativo un comentario según el cual para que el gobierno prosperara, tenía que demostrar que era capaz de mantener el ejército al margen de la política.
\end{abstract}

\section{La «primavera» polaca en "Cambio 16"}

\begin{abstract}
Año 1976
En Polonia se despertaba la resistencia al régimen. "C16" hizo referencia los disturbios en el artículo sobre la dependencia financiera del bloque oriental del mundo occidental, derivada de la doctrina de Henry Kissinger, "por encima y más allá de las cotidianas diatribas entre ambos sistemas, disparadas por los aparatos propagandísticos de uno y otro lado, para consumo popular" (S/N, 11-10-1976). Se anota que la subida de precios fue suplantada por aumento de controles en las exportaciones de los alimentos, pero el inicio de la defensa obrera organizada pasó desapercibido.
\end{abstract}




\section{Año 1977}

El espíritu de la solidaridad envolvía a círculos cada vez más amplios. Al parecer, la reanudación de las relaciones diplomáticas entre España y Polonia a principios del año motivó a "C16" mandar un enviado especial a este "eterno Estado colchón entre Rusia y Alemania" para "averiguar la verdadera naturaleza de esta nueva sociedad socialista" (Kelepikis, 6-11-1977). Este primer y algo confuso acercamiento de la revista a «la oveja rosada» del socialismo fue "exitosamente inspirada" por la embajada polaca en Madrid, que en el informe anual lo contabilizó como su logro en el ámbito de la información y propaganda (Archiwum Ministerstwa Spraw Zagranicznych, 1978: 18-19).

Los lectores españoles pudieron conocer el primer fruto de este viaje en noviembre. El primer artículo introduce al lector a este lejano y desconocido país y su historia muy reciente (Kelepikis, 6-11-1977). Además de las prometedoras perspectivas económicas y políticas de las relaciones bilaterales, quedó esbozado el milagro económico de Polonia: décimo lugar del mundo en la producción industrial, más de un millón de viviendas para parejas jóvenes, la importancia del sector privado en la producción agraria, aire de liberalización, sobre todos después de la amnistía, que fomentó "muchas ilusiones". Las causas de la crisis económica se explicaron como consecuencia de las tempestades meteorológicas y el "exacerbado consumismo" del polaco medio. Menciona también una forma alternativa que las polacas encontraron para suplir la falta de bienes: "coito eslavo" a cambio de petrodólares árabes. El siguiente artículo mantiene la misma línea (Kelepikis, 13-11-1977). Habló del cambio radical de la situación en el país tras la amnistía y de la democratización, aunque advirtió también que este "oasis de paz en el desierto político" podría acabar pronto, pues habitualmente la crisis económica conllevaba a las represiones. Se trató también el tema de la censura en el campo cultural, achacándola principalmente a la rutina administrativa. Además, el autor entrevistó a Jacek Kuroń y Adam Michnik de KOR para preguntarles por el fin de la organización tras la amnistía y habló de la Iglesia católica («omnipresente» y liderada por el "agresivo primado de Polonia", Wyszyński) y su postura ante el POUP y las reivindicaciones sociales. Su fuente al respecto era probablemente uno de los llamados curas-patriotas, bastante crítico que "no apreciaba las agresiones al régimen" por parte de la jerarquía y el ministro de relaciones entre el Estado y la Iglesia, Kazimierz Kąkol, quien aseguró que era ministro de paz y no de guerra. El enviado profundizó el tema de la Iglesia en una entrevista a Kąkol, quien le informó sobre la tolerancia del régimen hacia la Iglesia y las prácticas religiosas, la educación religiosa fuera de la escuela, mencionó los sacerdotes (patriotas) que cobraban su sueldo de las arcas del Estado y señaló a la incongruencia de los católicos quienes se casaban por la Iglesia (después de la boda civil), pero que luego no descartaban el divorcio: "No se toman muy en serio la moralidad religiosa" (Kelepikis, 18-12-1977). Llama atención, en el contexto del debate sobre el cambiante papel de la Iglesia en la sociedad española, que el artículo se titulase "Matrimonio civil" y acabase con un encabezado titulado "Divorciarse por la Iglesia".

\section{Año 1978}

Año de los primeros intentos de crear sindicatos independientes en las fábricas y astilleros y de la inesperada elección del arzobispo de Cracovia como papa. Para la sociedad ambos acontecimientos fueron fuente de gran alegría y esperanza; para el régimen suponían un problema de gran calado.

El primer enviado especial de "C16" debió irse todavía en 1977 pues Polonia no volvió a las páginas de la revista hasta después del cónclave. Al principio el corresponsal de Roma desestimó por simplistas las sugerencias de que fuera su procedencia de "un país eslavo, comunista y de una Iglesia sufrida" que condicionó su elección, aunque sí señaló que era de crucial importancia en la distensión global soviético-occidental y que las relaciones entre el Vaticano y los países comunistas iban a cambiar, pues ya no era necesario ningún intermediario (Carreras, 29-10-1978). En noviembre el semanario español ya tuvo un enviado nuevo para que recorriera las huellas polacas del papa y diera a conocer su infancia, juventud y la vida de uno de los más prominentes miembros de la «Iglesia del silencio». Fue una buena oportunidad para familiarizar los españoles con Polonia y su historia reciente (con referencias más objetivas que la anterior vez) (Comas, 5-11-1978b).

El nuevo corresponsal se dio cuenta de que los curas-patriotas y el círculo de Pax era una facción dentro de la Iglesia polaca sin ningún apoyo por parte de la jerarquía que, a su vez, rechazaba la denominación de la Iglesia silenciosa (Comas, 5-11-1978a). Observó que el papel de la Iglesia en la sociedad polaca era bien distinto del que ésta tuvo en España durante el franquismo, una observación muy importante para que los lectores no transpusieran sus referencias a una realidad totalmente distinta: "Aquí [en Polonia] la tradición tiene un sentido progresista, es un problema de existencia". Narró también la particular historia de Nowa Huta, la ciudad obrera cerca de Cracovia e intentó explicar la paradoja de los comunistas polacos que le fue contada: "pongamos que el Partido es más importante para esta vida y la Iglesia para la otra". En efecto, la complejidad de Polonia suscitó interés y reflexión de los lectores. 


\section{Año 1979}

La situación económica y social se hacía insostenible. Cierto alivio espiritual y grandes esperanzas para el pueblo trajo la peregrinación del papa a su tierra natal que tuvo lugar en junio. Durante todo el año "C16" no publicó ningún artículo sobre Polonia.

\section{Año 1980}

La "renovación" polaca, materializada en la fundación del sindicato libre "Solidaridad", atrajo un disparo de comentarios (más de 30, se citan solamente los más relevantes) del "C16" sobre el país: "en los últimos tiempos (...) todo pasa allí: papas, premios Nobel, sindicatos independientes, sin olvidar el Pacto de Varsovia" (S/N, 26-10-1980). Su contenido se puede dividir en dos categorías. La primera estuvo relacionada con asuntos políticos, económicos y sociales del país. Así, todavía antes de empezar la huelga de Gdańsk, se habló sobre la crisis económica originada en la dependencia de la URSS (Mas, 5-04-1980). Desde agosto, los lectores recibían informaciones mucho más extensas sobre la realidad polaca: las causas de las huelgas "en un país donde la ideología oficial dice que las huelgas no existen", su desarrollo, las demandas de los huelguistas y las actuaciones del régimen que reconoció haberse alejado del pueblo y formó un nuevo equipo de corte "reformista" (S/N, 31-08-1980; S/N, 7-09-1980; Comas, 21-09-1980a; 6-12-1980; 15-12-1980 a y b). Mucho interés fue puesto en la figura de Wałęsa, destacando sus actos de devoción en público y el significado del catolicismo y la Iglesia para el pueblo polaco y la "renovación" que vivía (Comas, 14-09-1980 \& 21-09-1980b). La segunda categoría concernía la amenaza de la invasión soviética a Polonia -que revocaba los sucesos de Hungría del 1956 y Praga de 1968- y añadía relevancia internacional y gran dramatismo a las noticias sobre Polonia ("si los tanques irrumpen en Polonia, sería el comienzo de la tercera guerra mundial" [cita del disidente soviético Petro Grigorenko durante la Conferencia sobre la Seguridad y Cooperación en Europa (CSCE) de Madrid; S/N, 24-11-1980]; o "el sueño de Fidel es entrar en Europa, con permiso de los rusos. Polonia puede ser, en efecto, el pretexto" (Pasamar, Álvarez Vara \& Kelepikis, 15-12-1980]), que de lo contrario serían quizás de no demasiado interés para el público español, ocupado con problemas mutatis mutandis parecidos que los polacos (Comas, 27-10-1980 \& 17-11-1980; S/N, 8-12-1980; Utrilla, 15-12-1980; Valenzuela, 1512-1980). Al final del año el enviado especial a Varsovia admitió que la probabilidad que una invasión era menor de lo que hicieron aparentar los medios de comunicación occidentales (Comas, 22-12-1980a). Para quitar el miedo, pero mantener el suspense añadió otro material con el escalofriante título "Tanques rusos en Polonia" que resultó tratar de una película de Krzysztof Zanussi sobre la vida de Juan Pablo II (Comas, 22-121980b). Irónicamente, una de las tomas de esta película reproducidas en dicho artículo volverá a ser usada "en serio" durante el estado de ley marcial (Comas, 16-03-1981). Finalmente, conviene mencionar el algo amargo comentario sobre el premio Nobel de literatura de aquel año, Czesław Miłosz: "un poeta difícil y minoritario, pero que tiene virtud de ser polaco" (S/N, 26-10-1980).

\section{Año 1981}

Después de año y medio de «carnaval de la democracia»: una muestra de libertades sindicales, prensa independiente e iniciativas políticas vino la cuaresma. Durante el otoño el régimen, al margen de las divisiones internas, preparaba la introducción de la ley marcial. Wojciech Jaruzelski recurrió a la amenaza soviética, sin que Moscú compartiera la idea, para justificar que su operación -iniciada el 13 de diciembre-era imprescindible para salvar el país (Dudek, 2003). La violenta pacificación de una mina en Silesia sirvió de manifestación de fuerza y determinación del régimen.

Las extraordinariamente numerosas (más de 60) narrativas de "C16" sobre Polonia siguieron estando envueltas en el ambiente de la amenaza de la invasión soviética, situando la crisis polaca en el centro de la carrera armamentística, lo cual producía una "mezcla explosiva" (Algañaraz, 20-04-1981 a y b), pronosticando una posible "guerra psicológica" (Comas, 19-01-1981) o aludiendo a 1939 cuando Polonia "actuó de detonante de la última guerra mundial" (Comas, 6-04-1981). Se indagó, consultando diferentes expertos, las similitudes y diferencias entre Polonia y Checoslovaquia para prever una posible invasión, pero sus opiniones divergían (Comas, 9-02-1981 en contra de esta hipótesis; Liehm, 9-03-1981 a favor de ella). El interés se centró en torno a los tres agentes más importantes del tablero polaco: el partido, la Iglesia y los sindicatos ( $\mathrm{S} / \mathrm{N}, 14-09-1981$; Ferreras, 5-10-1981; 19-10-1981 \& 14-12-1981; S/N, 16-11-1981). Según la revista, los dos primeros estaban unidos en un "matrimonio de conveniencia", siendo la Iglesia el más firme aliado del POUP, cosa que producía decepción y descontento entre los obreros (Comas, 5-01-1981). Los cambios que se produjeron en la cúspide del partido la dejaron en manos de reformistas, tales como Kania, Jaruzelski, general del ejército que gozaba en Polonia de "prestigio y cariño" y se había resistido a la corrupción (S/N, 26-10-1981; Ferreras, 2-11-1981 \& 9-11-1981) y Rakowski, "el hombre más abierto al diálogo" (S/N, 23-02-1981; S/N, 27-07-1981; Algañaraz J.C., 15-06-1981; Algañaraz J., 17-08-1981). Entre los problemas más urgentes estaba la situación económica: problemas de abastecimiento (paliados con ayudas de los países occidentales) y la insolvencia para pagar 
la deuda extranjera (Comas, 16-03-1981; Algañaraz, 17-08-1981; Utrilla, 13-07-1981; Ferreras, 7-12-1981). Además, una atención especial le fue dedicada a lo largo del año a Wałęsa, el "héroe", "hombre de hierro" y otro, después del papa superstar de la realidad polaca (Hidalgo, 26-10-1981; Ibáñez Martín, 15-06-1981), tanto a su vida pública, como privada: desde su viaje a Vaticano, donde además del papa se reunió con su propio padre (S/N, [Nota de prensa], 19-01-1981), el proyecto de su viaje a España (S/N, [Nota de prensa], 16-03-1981), sus decisiones como dirigente del ala moderada de "Solidaridad", hasta su fiesta de noche vieja (S/N, [Nota de prensa], 19-01-1981). Finalmente, hay que mencionar un extenso y completo reportaje sobre Varsovia, incardinado dentro del ciclo sobre las ciudades comunistas, que acercaba a los lectores a la austera y grisácea vida cotidiana de los habitantes de la capital polaca, en las calles y dentro de sus casas (Bergés, 25-05-1981). El discurso sobre Jaruzelski cambió radicalmente tras la introducción de la ley marcial y desde entonces será visto como el "Pinochet rojo polaco", o Pinochelski (Utrilla, 21-12-1981). Se hizo hincapié en la ya casi tradicional soledad de Polonia ante las adversidades históricas, como esta (Egurbide, 21-12-1981). Una vez más en la historia, Polonia dejaba de existir (Tomás de Salas, 28-12-1981) y volvían a aparecer en los medios los campos de concentración, esta vez para internar a los activistas (Algañaraz \& Cid, 28-12-1981). La Iglesia, respaldada por el papa, daba apoyo a los oprimidos. El año acabó con un gran dramatismo: 45 mil personas detenidas en los primeros días, suicidios y la amenaza de un nuevo holocausto (Algañaraz \& Cid, 28-12-1981). En realidad, fueron privados de libertad 10 mil ciudadanos. El presunto suicida, Krzysztof Śliwiński, vive hasta hoy en día.

\section{Año 1982}

Polonia quedó sumergida durante todo el año en la "guerra del régimen contra la nación". La ley marcial no fue suspendida hasta el 31 de diciembre. Para su levantamiento había que esperar hasta julio del año siguiente. Para el inicio de los verdaderos cambios, unos cinco años más.

"Aplastada la primavera polaca" (S/N, 4-01-1982), "C16" mostró una profunda empatía con los refugiados que abandonaron el país y esperaban un futuro mejor en Austria (Cid, 4-01-1982), y también con los que se quedaron -en libertad o no- y prosiguieron con la resistencia (Egurbide, 25-01-1982; Algañaraz, J.C., 1-02-1982; Algañaraz, J., 10-05-1982; Ferreras, 24-05-1982), sobre todo tras la ilegalización de "Solidaridad" (Ferreras, 11-10-1982; 18-10-1982 \& 1-11-1982; S/N, 25-10-1982). La liberación de Wałęsa y su postura conciliadora fue muy bien recibida. No lo fue tanto, en cambio, la «neutralidad» de la Iglesia (S/N, 22-111982; Ferreras, 27-12-1982). Los -acertados- pronósticos para los próximos meses no eran muy alentadores para la redacción del "C16": "decididamente, Polonia, aun sin ley marcial, continuará lo mismo" (Ferreras, 27-12-1982).

\section{Conclusiones}

Los susodichos contenidos periodísticos permiten reflexionar acerca de la paradoja señalada por Rupérez de las simultáneas diferencias y similitudes entre España y Polonia. La agenda establecida durante el septenio del cambio 1976-1982 por los semanarios políticos "C16" y "P" sobre Polonia y España respectivamente permite observar una confluencia de contenidos y de sus pragmáticos encuadres. La agenda que establecían los respectivos semanarios políticos reflejaba claramente sus líneas editoriales. Así, en lo general y a modo de espejo, "C16" se interesaba sobre todo por la triada polaca: el POUP, la Iglesia y los sindicatos, mientras que "P" lo hacía sobre la triada española: la burguesía, las fuerzas armadas y la Iglesia, además de la situación de la izquierda y, más como curiosidad, los separatismos y el terrorismo. Es en el encuadre, o framing, cuando la imagen plasmada en los artículos, a menudo entre líneas, adquiría ciertos rasgos de espejismos de la situación doméstica. 
Figura 2. Resumen del contenido informativo publicado por "P" sobre España y

"C16" sobre Polonia entre 1976-1982 y su encuadre interpretativo

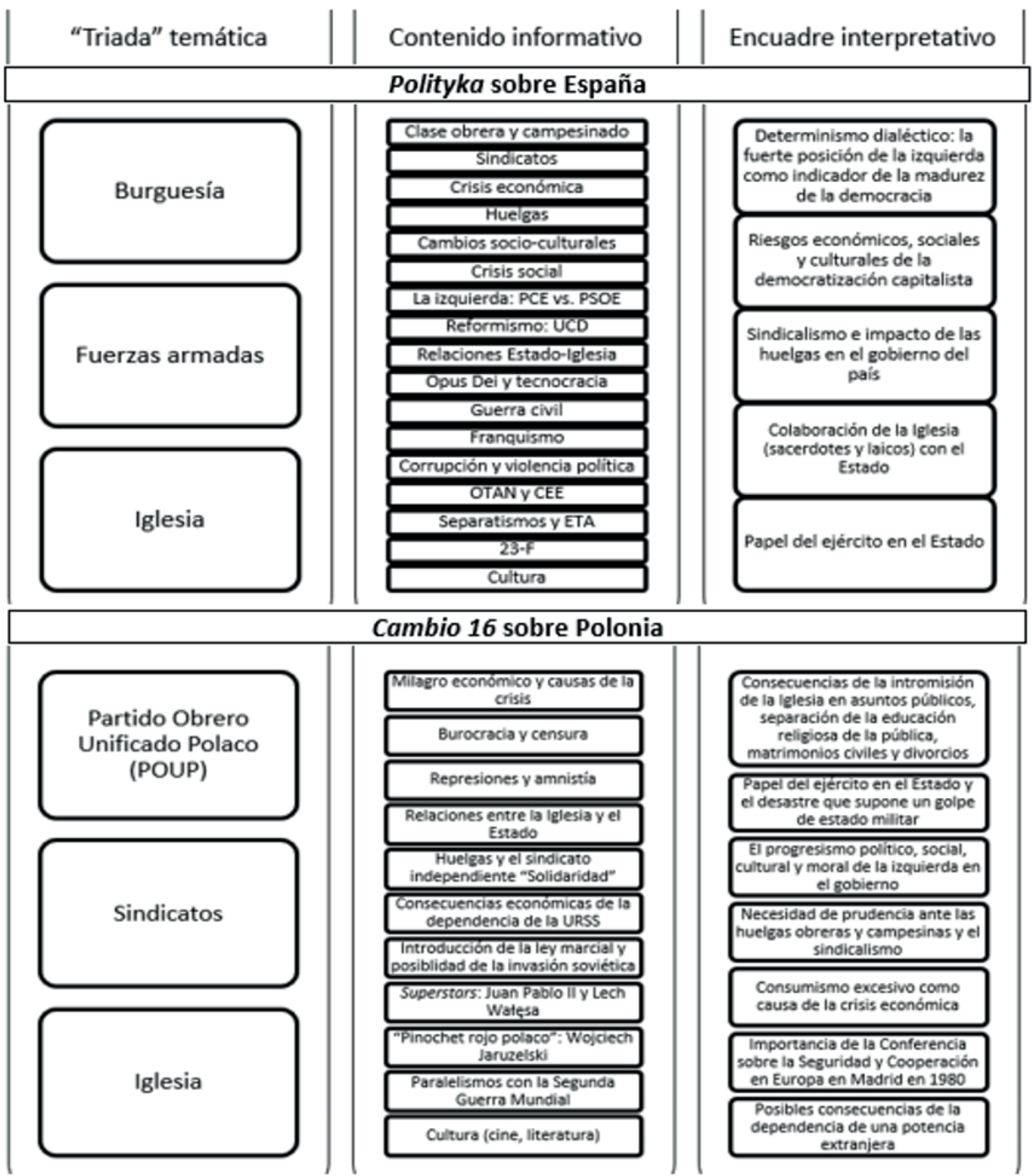

Fuente: elaboración propia

Ambos semanarios subrayaban -desde sus propias ópticas: capitalista y real socialista- que la democracia era algo totalmente nuevo y el aprendizaje iba a ser prolongado. A lo largo de la frustrada revolución democrática nacional los polacos tomaban "sus primeras clases de vida política de manera empírica" (Kelepikis, 13-111977). La ley marcial introducida por «Pinochelski» fue utilizada para ilustrar los desastres que podría provocar la toma del mando por los militares si el 23-F hubiese tenido éxito. Los españoles, por su parte, tenían que romper con la dictadura como "la única realidad política que conocían" (Ikonowicz, 6-12-1975) y seguir el proceso determinista desde ésta hacia una democracia de izquierdas (Ikonowicz, 25-06-1977), camino por el cual Polonia -según se quería hacer creer a los lectores- ya había pasado. Esta dialéctica se vio amenazada, sin embargo, por la entrada de España a la OTAN. Otra debilidad fue su carácter capitalista, de cuyos peligros (huelgas, crisis económica crónica) "P" advertía en numerosas ocasiones - un claro espejismo de las nuevas dinámicas ocurrentes en la propia Polonia. Muy sugerente resulta también el mutuo interés por las relaciones entre el Estado y la Iglesia. Mientras que "C16" era muy crítico con la primero "agresiva" y luego "silenciosa" Iglesia polaca, para "P" la Iglesia española era un ejemplo a seguir: una sumisa colaboradora del Estado que llegó a aceptar que los sacerdotes pertenecieran al partido comunista (Kedaj, 7-08-1976). Aún más lo era Opus 
Dei que, según daba a entender la revista, eran lo que el régimen polaco necesitaba: tecnócratas vinculados al mismo tiempo a la Iglesia y al servicio del Estado.

En definitiva, se puede concluir que los encuadres interpretativos de los contenidos informativos sobre Polonia y España respectivamente fueron a menudo utilizados para estructurar las percepciones sociales de asuntos propios.

\section{Referencias bibliográficas}

Algañaraz, J.C. "Eurocóctel con misiles", Cambio 16, n490, 20-04-1981a.

— "Polonia: entre la quiebra y la invasión", C16, n490, 20-04-1981b.

— "La herejía polaca", C16, nº498, 15-06-1981.

— "El Gulag de Pinochelski", C16, n535, 1-02-1982.

Algañaraz, J., "Polonia, un mal año", C16, n507, 17-08-1981.

— "Polonia no se rinde", C16, n545, 10-05-1982.

Algañaraz; J., Cid, R., "Nieve, sangre y terror", C16, n526, 28-12-1981.

Archiwum ministerstwa spraw zagranicznych (1978), “Raport polityczny ambasady PRL w Madrycie za rok 1977”, D.IV. Hp.242-1-77.

Barabasz, A. (2016). "PRL wobec rozszerzenia Wspólnot Europejskich o Hiszpanię i Portugalię (1962-1986)". En: Rocznik Integracji Europejskiej, nº10. pp. 317-334.

Bednarczuk, M. (2008). Obraz hiszpańskiej wojny domowej lat 1936-1939 w piśmiennictwie polskim. Toruń: Wyd. Adam Marszałek.

Bergès, Y.-G., "Las ciudades rojas I: Varsovia", C16, nº495, 25-05-1981.

Bernatowicz-bierut, G. (1978). Hiszpania we wspótczesnym świecie, 1945-1975. Warszawa: PWN.

— "Hiszpania - szesnasty sojusznik", Polityka, n¹307, 22-05-1982.

— "Po raz pierwszy od 1936", $P, \mathrm{n}^{\circ} 1331,6-11-1982$.

Białokur, M., Jakóbczyk-Adamczyk, P. (eds.) (2012). Polska a Hiszpania. Z dziejów koegzystencji dwóch narodów w XX w. Toruń-Opole-Piotrków Trybunalski: Dom Wydawniczy DUET.

Carreras M., "El Papa que vino del Este", C16, n³60, 29-10-1978.

Cid, R., "El éxodo polaco", C16, n527, 4-01-1982.

Cohen, B. C. (1963). The Press and Foreign Policy. Princeton: Princeton University Press.

- (1970). “The Relationship between Public Opinion and Foreign Policy Maker”. En: SMALL, M. (dir.), Public Opinion and Historians. Detroit: Wayne State University, pp. 65-80.

Comas, J., "La Iglesia del silencio se hace oír", C16, n³61, 5-11-1978a.

— "La larga marcha de un cura polaco", C16, n³61, 5-11-1978b.

— "El milagro polaco", C16, n458, 14-09-1980.

— "La primavera de Varsovia", C16, n²59, 21-09-1980a.

— "Lech Walesa: «sólo soy un sindicalista»", C16, nº459, 21-09-1980b.

— "Crece el muro", C16, n455, 27-10-1980.

— "Dos poderes en Polonia", C16, n468, 17-11-1980.

— "La hora de la autocrítica (entrevista a Mieczysław Rakowski, director de Polityka)", C16, nº71, 6-12-1980.

— "Entre Kania y el tío Vania", C16, nº72, 15-12-1980a.

— "Católicos al poder", C16, n'472, 15-12-1980b.

— "Los rusos blanden látigo", C16, nº73, 22-12-1980a.

_ "Tanques rusos en Polonia", C16, n473, 22-12-1980b.

— "La cruz y el martillo", C16, no475, 5-01-1981.

— "Polonia, en la cuerda floja", C16, n477, 19-01-1981.

— "Un modelo político para Polonia", C16, nº480, 9-02-1981.

— "Otra vez Polonia al rojo vivo", $C 16, \mathrm{n}^{\circ} 485,16-03-1981$.

— "El precipicio polaco", C16, n488, 6-04-1981.

Czajka, M. (1980). "Polska opinia publiczna wobec wojny domowej w Hiszpanii 1936-1937”. En: Przeglad Historyczny, n 71 , pp. 253-275

Díaz Dorronsoro, J. M. (2010). “The origins the Spanish newsmagazine C16 (1971-1974)”. En: Communication \& Society, no23, pp. 41-70.

- (2012). C16. Historia de la mítica revista de la Transición democrática española, en el $40^{\circ}$ aniversario de su fundación. Madrid: Leer/Artículo XIX.

Dobek-Ostrowska, B. (1996). "La transición democrática en España y Polonia (análisis comparativo)". En: Investigaciones Históricas, nº 16, pp. 239-256.

Dudeka, A. (2003). Stan wojenny w Polsce 1981-1983. Warszawa: Instytut Pamięci Narodowej.

Egurbide, P., "Polonia triste y sola", C16, n525, 21-12-1981.

- "Occidente cierra filas", C16, n⿳5530, 25-01-1982. 
Faraldo, J.M. (2016). "El año del fútbol. La emigración polaca en España y algunas iniciativas de solidaridad con Solidarność (1981-1989)”. En: Cuadernos de Historia Contemporánea, n³8, núm. esp.), pp. 77-90.

Ferreras, V. M., "La crisis que no cesa", C16, n514, 5-10-1981.

— "Solidaridad se modera", C16, n516, 19-10-1981.

_ "La última carta en Polonia", C16, n516, 2-11-1981.

_ “El prestigio Jaruzelski”, C16, n519, 9-11-1981.

_ "Una autocrítica polaca", C16, n²3, 7-12-1981.

_ "Walesa no quiere gobernar", C16, n524, 14-12-1981.

_ "Varsovia, primavera ardiente", C16, n547, 24-05-1982.

— "Otro golpe de Pinochelsky", C16, n567, 11-10-1982.

— "Resistencia obrera", C16, n568, 18-10-1982.

— "Contra viento y marea", C16, nº570, 1-11-1982.

_ "Pinochelski no afloja", C16, n578, 27-12-1982.

González Martínez, E., Nalewajko, M. (coords.) (2005). España y Polonia: los encuentros. Madrid: CSIC.

Górnicki, W., "Na śmierć tyrana", $P$, nº78, 29-11-1975.

Haubrich, W., "Morderstwa nie da się ukryć”, $P$, n969, 27-09-1975.

Hidalgo, M., "Informe sobre Polonia", C16, n517, 26-10-1981.

Historia del Partido Comunista de España (versión abreviada). (1960). Warszawa: Ediciones «Polonia».

Hübner, D., "Manipulowanie termometrem”, $P$, nº80, 13-12-1975.

Ibáñez M., Francisco, "Walesa superstar”, C16, n498, 15-06-1981.

Ikonowicz, M., "Przez monarchię do demokracji?”, $P$, nº79, 6-12-1975.

— "Wojsko przestaje być zagadką", $P$, n986, 24-01-1976.

— “Iberyjska Playa Girón”, P, nº1010, 10-07-1976.

— "Zapobiec katastrofie", $P$, n⿳1027, 6-11-1976.

— "Władza widzialna i niewidzialna", $P, \mathrm{n}^{\circ} 1043,26-02-1977$.

— "Czerwone sztandary w Madrycie", P, nº1051, 23-04-1977.

_ “Frankizm nie przeżył”, $P$, no1060, 25-06-1977.

— "Żadnych barykad i ułomki bunkra", $P$, nº1088, 7-01-1978.

— "Suarez na kolumnie", $P$, nº1095, 25-02-1978.

— "Bezrobotnego pogłaskać", P, nº1097, 11-03-1978.

— "Rozwód zdrowy dla religii", $P$, n¹110, 10-06-1978.

— "Ultragalatyka", $P, \mathrm{n}^{\circ} 1135,2-12-1978$.

— "Pusto w bunkrze", $P$, no1150, 17-03-1979.

— "Wielki spektakl hiszpańskiej demokracji", $P$, nº1215, 14-06-1980.

— "Hiszpańska intentona", $P$, nº1253, 7-03-1981.

Ikonowicz, P. I., "Portret dyktatora przez sekretarza sporządzony”, P, nº1190, 22-29-12-1979.

Iwiński, T., "Reżim usiłuje przetrwać”, $P$, n975, 8-11-1975.

Iyengar, S. (1991). Is anyone responsible? How television frames political issues. Chicago: University of Chicago Press. Jaranowski, M., "Klątwa nad Baskami”, $P$, nº70, 4-10-1975.

Kałużyński, Z., "Namiętność też jest iluzją", $P$, no1153, 7-04-1979.

Kania, D., Targalski, J., Marosz, M. (2013). Resortowe dzieci. Media. Warszawa: Wyd. Fronda.

Kedaj, W., "Wyjście na powierzchnię", $P$, n¹014, 7-08-1976.

Kelepikis, A., "La oveja rosada", C16, n³08, 6-11-1977.

— "Nuestra señora del partido comunista", C16, n³09, 13-11-1977.

— "Matrimonio civil", C16, n³14, 18-12-1977.

Kieniewicz, J. (2001). Hiszpania w zwierciadle polskim. Gdańsk: Novus Orbis.

- (ed.) (2004). Studia polsko-hiszpańskie. Wiek XX. Warszawa: Uniwersytet Warszawski.

Kik, K., "Podziały na lewicy", $P$, nº1267, 13-06-1981.

— "Komuniści bez jedności”, $P$, n⿳11298, 20-03-1982.

— "Czy rządzić będą socjaliści”, $P$, nº1310, 12-06-1982.

— "Po przegranej", $P$, nº1333, 20-11-1982.

— "Jeszcze jeden reformista", $P, \mathrm{n}^{\circ} 1336,11-12-1982$.

Kudełko, J., Taracha, C. (coords.) (2012). Polonia-España. Ayer y hoy. Estudios sobre algunos aspectos del pasado y de la actualidad. Lublin: Werset.

Lach, R., “Oczy nie od parady”, P, nº1154, 14-04-1979.

Liehm, A. J., "Lecciones de Praga para Polonia”, C16, n484, 9-03-1981.

López Pintor, R. (1982). La opinión pública española: del franquismo a la democracia. Madrid: CSIC.

Łuszczkiewicz, M., “Gospodarczy kompleks Hiszpana”, P, nº1151, 24-03-1979.

Malinowski, M., Niwiński, P., Dmochowski, T. (dirs.) (2003). "Media w PRL, PRL w mediach”: materiaty z II Ogólnopolskiej Konferencji „Propaganda PRL-u”; Gdańsk, 19-20 listopada 2003. Gdańsk: Uniwerstytet GdańskiInstytut Pamięci Narodowej. 
Marina, J. D. (coord.) (2008). El cambio de la imagen mutua de Polonia y España desde la transición. Warszawa: Instituto Cervantes-IH PAN.

Marrodan Casas, C., SCHMIDT, B., “Już nie zakazane owoce”, $P$, n$^{\circ} 1094,18-02-1978$.

Mas, F., "Vientos del Este, tormenta de crisis", C16, n435, 5-04-1980.

McCombs, M. (1996). "Influencia de las noticias sobre nuestras imágenes del mundo". En: Bryant, J., Zillmann, D. (dirs.), Los efectos de los medios de comunicación. Investigaciones y teorías, trad. Montserrat Basté-Kraan, Barcelona: Paidós, pp. 13-34.

- (2004). Setting the Agenda. The Mass Media and the Public Opinion. Cambridge: Polity Press.

Miret Magdalena, E., "Juan Pablo Super-Star", Triunfo, no856 (06.1979), p. 14.

Mizerska-Wrotkowska, M., Orella Martínez, J. L. (eds.) (2014). Poland and Spain in Contemporary World, Madrid: Schedas.

Mleczak, M. (2013). “Stosunki polsko-hiszpańskie 1939-1975”. En: Studenckie Zeszyty Naukowe Uniwersytetu Jagiellońskiego, $\mathrm{n}^{\circ} 10$, pp. 79-95.

Opioła, W. (2016). Hiszpańska wojna domowa w polskich dyskursach politycznych. Analiza publicystyki 1936-2015. Opole: Uniwersytet Opolski.

Pasamar, L., Álvarez Vara, I., Kelepikis, A., "Yo disiento", C16, n472, 15-12-1980.

Pasierbiński, T., "Zachmurzenie wzrasta", $P$, nº1098, 18-03-1978.

Passent, D., “Zabrakło gazet w Madrycie”, $P$, nº70, 4-10-1975.

Pérez López, P. (1997). “Środki masowego przekazu w Hiszpanii w latach 1975-1995”. En: Dobek-Ostrowska, B. (dir.), Współczesne systemy komunikowania. Wrocław: Wyd. Uniwersytetu Wrocławskiego, pp. 91-111

Pons, J., "List do redakcji", $P$, nº1108, 27-05-1978.

Reese, S.d., Gandy, Jr., O.h., Grant A.E. (eds.) (2001). Framing Public Life: Perspectives on Media and Our Understanding of the Social World. NJ: Lawrence Erlbaum Associates.

Romanowicz, B., “Opowieści niemoralne”, P, nº1102, 15-06-1978.

Różycki, B. (2015). Polska Ludowa wobec Hiszpanii frankistowskiej i hiszpańskiej transformacji ustrojowej, $1945-1977$. Warszawa: Instytut Pamięci Narodowej.

Rubio Fuentes, J. M. (2009). “Opinión pública y medios de comunicación. Teoría de la agenda setting”. En: Gazeta de Antropología, $\mathrm{n}^{\mathrm{0}} 25, \mathrm{~s} / \mathrm{p}$.

Rumińska, E., “'Dalanim” — spółka nietypowa”, P, nº1159, 19-05-1979.

Rupérez J. (2012). "España de los años 60”. Introducción a: Laforet, C., Za żelazną kurtyną. Podróż do Polski w 1967 roku, González Caizán, C. (ed.), trad. Filip Łobodziński, Warszawa: Iskry.

Ryszka, F., "Hiszpanie przeciw Hiszpanom”, P, n¹010, 10-07-1976.

S/N, "Telex mundial: Varsovia", C16, n¹86, 30-06-1975.

$\mathrm{S} / \mathrm{N}$, "Este Europeo: Los millones de los capitalistas", C16, n²53, 11-10-1976.

$\mathrm{S} / \mathrm{N}$, "El reto de Varsovia", C16, n456, 31-08-1980.

$\mathrm{S} / \mathrm{N}$, "Ruedan cabezas", $C 16, \mathrm{n}^{\circ} 457,7-09-1980$.

$\mathrm{S} / \mathrm{N}$, "Un oscuro poeta", C16, n464, 26-10-1980.

S/N, "Madrid, congresos mil", C16, n469, 24-11-1980.

$\mathrm{S} / \mathrm{N}$, "En el filo de la navaja", $C 16, \mathrm{n}^{\circ} 471,8-12-1980$.

$\mathrm{S} / \mathrm{N}$, [Nota de prensa], C16, n477, 19-01-1981.

$\mathrm{S} / \mathrm{N}$, "Las últimas bazas", $C 16, \mathrm{n}^{\circ} 482,23-02-1981$.

$\mathrm{S} / \mathrm{N}$, [Nota de prensa], C16, n485, 16-03-1981.

S/N, "Polonia: el difícil equilibrio", C16, n504, 27-07-1981.

S/N, "Solidaridad alternativa", C16, n511, 14-09-1981.

$\mathrm{S} / \mathrm{N}$, "Cambio de guardia", C16, n'517, 26-10-1981.

$\mathrm{S} / \mathrm{N}$, "Walesa, contra el desorden", C16, n520, 16-11-1981.

$\mathrm{S} / \mathrm{N}$, "Primavera rota", C16, n527, 4-01-1982.

S/N, "Polonesa heroica", C16, nº569, 25-10-1982.

S/N, "Libertad sin ira", C16, n573, 22-11-1382.

Sádaba Garraza, T. (2008). Framing, el encuadre de las noticias: el binomio terrorismo-medios. Buenos Aires: La Crujía.

Scheufele, D. A. (2000). "Agenda-setting, priming, and framing revisited: another look at cognitive effects of political communication". En: Mass Communication \& Society, n³, pp. 297-316.

Skulska, W., "W pełnym świetle", $P, n^{\circ} 1004,29-05-1976$.

— "Plamy białe i czarne", $P$, n$^{\circ} 1145,10-02-1979$.

— “Samodzielność, niezależność i tolerancja”, $P$, nº1275, 8-08-1981.

Tomás de Salas, J., "Polonia no existe", C16, n526, 28-12-1981.

Urban, J., "Bomby nie było", $P$, nº1178, 29-09-1979.

Utrilla, R., "Polonia entre dos polos", C16, n472, 15-12-1980.

— "Polonia en la estacada", C16, nº502, 13-07-1981.

_ “Tanques redentores", C16, n'525, 21-12-1981.

Valenzuela, E., "Alarma en Washington", C16, n472, 15-12-1980. 
Władyka, W. (2007). Polityka i jej ludzie. Warszawa: POLITYKA Spółdzielnia Pracy.

Wojna, B. (2004). La política de seguridad en España y en Polonia en la transición hacia la democracia: un análisis comparado. Madrid: Universidad Complutense.

Wolsza, T., Ligarski, S. (dirs.) (2010). Dziennikarze władzy, władza dziennikarzom. Aparat represji wobec środowiska dziennikarskiego 1945-1990. Warszawa: Instytut Pamięci Narodowej, 2010.

Zdanowski, H., “Hiszpańska panorama”, $P$, nº76, 15-11-1795. 